\title{
Emerging country pharmacology: a 10-year perspective from Naunyn-Schmiedeberg's Archives of Pharmacology
}

\author{
Marcio M. Coelho • Irmgard Tegeder • Martin C. Michel
}

Received: 24 May 2011 / Accepted: 24 May 2011 / Published online: 9 June 2011

(C) The Author(s) 2011. This article is published with open access at Springerlink.com

Having been founded in 1873 as Archiv für experimentelle Pathologie und Pharmakologie, Naunyn-Schmiedeberg's Archives of Pharmacology is the oldest existing pharmacology journal. Historically, it has been a flagship journal for German language pharmacology but following publication of papers in English since 1973, it has increasingly become international (Starke 1998). In the past, most published primary research in this and many other leading pharmacology journals came from Western Europe, Northern America and Japan, but in recent years, other parts of the world increasingly contribute to the advancement of pharmacological knowledge. To explore how this is reflected in the pharmacological literature, we have compared the countries of origin of published papers in Naunyn-Schmiedebergśs Archives of Pharmacology in 2001 and 2010.

In 2001, the journal published papers with authors from 33 countries. The vast majority of authorships (71\%) came from Western European countries including 30\% from Germany, $10 \%$ from Italy, $7 \%$ from France, $5 \%$ from the UK, and 3-4\% each from Sweden, the Netherlands and Spain. Classical strongholds of pharmacology research such as North America and Japan contributed 3\% and 9\% of

M. M. Coelho

School of Pharmacy, Universidade Federal de Minas Gerais,

Belo Horizonte, Brazil

I. Tegeder

pharmazentrum frankfurt/ZAFES, Department of Clinical

Pharmacology, University of Frankfurt,

Frankfurt, Germany

M. C. Michel ( $\square)$

Department of Pharmacology \& Pharmacotherapy, Academic

Medical Center, University of Amsterdam,

1105 AZ Amsterdam, Netherlands

e-mail: martincmichel@yahoo.de authorships, respectively. In contrast, the rest of Australasia contributed 8\% (including 3\% from Australia), Eastern Europe 6\% and Latin America 3\% (Fig. 1).

A very different picture emerges for 2010, in which authors of published papers originated from 28 countries (Fig. 1). The contribution of Western Europe declined but remained strong ( $44 \%$ of all published papers) including $24 \%$ from Germany, $6 \%$ from Italy, and 5\% from the UK. North America and Japan contributed $4 \%$ and $7 \%$, respectively. In contrast, other regions increased their contributions in both percentage and in absolute numbers. Thus, Australasia (other than Japan) contributed 23\% of papers, with Taiwan having 7\% (slightly passing Japan), India and the People's Republic of China 5\% and South Korea $4 \%$. Latin America increased to $10 \%$ of published papers, all but one originating from Brazil. Eastern Europe had an $11 \%$ share, largely driven by papers from Poland. Thus, in 2001, the five countries contributing to most published papers were Germany, Italy, Japan, France and the UK. In contrast, in 2010, the countries contributing most were Germany, Brazil, Taiwan, Japan with Italy and Poland sharing the fifth position.

This trend for greater globalization until now is only partly reflected in the changing composition of the editorial board. In 2001, all 18 editors of the journal came from Western Europe, and also the editorial board at large consisted almost exclusively of Western European scientists (59\% Germans), except for one board member each from Japan, Eastern Europe and the USA. However, in 2010 out of 18 editors now only $78 \%$ come from Western Europe, and three from Australasia and two from Northern America. Among the editorial board at large, $78 \%$ come from Western Europe (including 52\% from Germany), whereas Australasia, Northern America and Latin America are represented by $14 \%, 10 \%$ and $2 \%$, respectively. 


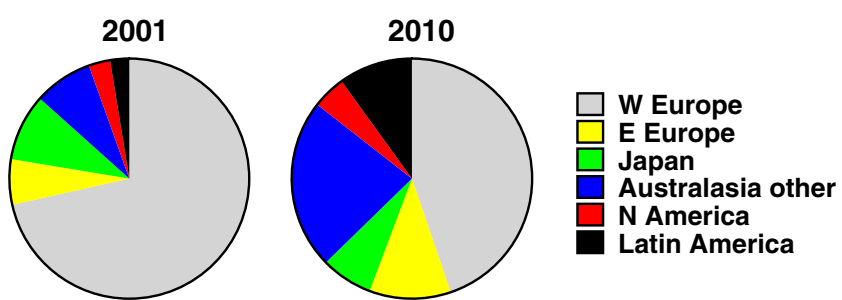

Fig. 1 Relative contributions of various regions to published papers in Naunyn-Schmiedeberg's Archives of Pharmacology in 2001 and 2010. Note that the relative gains of Australasia are similarly due to those of Taiwan, People's Republic of China, South Korea and India, whereas those of Latin America are almost exclusively due to increased authorship from Brazil. Papers with authors from multiple countries were counted with an equal share for each contributing country

Given that among the emerging market countries, Brazil showed the strongest gain in published papers in the comparison of 2001 and 2010 and actually became the second most publishing country in the journal in 2010, it may be of interest to analyze how this growing contribution came about and which topics were of interest to Brazilian pharmacologists.

Historically, one of the most important steps in the consolidation of Brazilian pharmacology was the foundation of the Department of Pharmacology of the Medical School of Ribeirão Preto, University of São Paulo, in 1955. That department was initially led by an invited Austrian researcher, Professor Gerhard Werner, before the arrival of the best known Brazilian pharmacologist, Professor Maurício Rocha e Silva, in 1957. Certainly, the biggest contribution of Rocha e Silva and his close collaborators, Wilson Beraldo and Gastão Rosenfeld, was the discovery of the nonapeptide bradykinin that occurred approximately 8 years before joining that department while working at the Biological Institute in São Paulo (Rocha E Silva et al. 1949). The discovery of this peptide and the characterization of its multiple activities certainly influenced many pharmacologists in the country over the following years until today, reflected in the classically strongest research themes in Brazilian pharmacology: pain and inflammation, control of cardiovascular functions and activities of animal toxins. There is no doubt that the great Brazilian biodiversity, the country being home to $15-20 \%$ of the total number of species on the planet, also influenced Brazilian pharmacology over the last decades. This is reflected by the great interest of many pharmacologists in the identification and characterization of biological activities of natural products derived mainly from plants, arthropods and reptiles. Unfortunately, standardized analysis of the chemical or biological constituents of the extracts often lags behind the behavioural testing and hence validation and comparability of the results often remain elusive. This limits the international interest and visibility of this research. Indeed this heritage is seen prominently in submissions to Naunyn-Schmiedeberg's Archives of Pharmacology, as manuscripts related to extracts of and compounds derived from Brazilian animals and plants dominate submissions, particularly those related to pain and inflammation.

Another initiative that markedly contributed to the consolidation of Brazilian pharmacology was the foundation of the Brazilian Society of Pharmacology and Experimental Therapeutics (SBFTE) in 1966. Nowadays, SBFTE, a member of the International Union of Basic and Clinical Pharmacology, has more than 1,000 members and this number increases quickly. Each year, SBFTE organizes an important congress in which known Brazilian and foreign pharmacologists are invited to give lectures on relevant and current pharmacological themes. This event is attended by a great number of pharmacologists and also $\mathrm{PhD}, \mathrm{MSc}$ and undergraduate students of pharmacology coming from departments or laboratories of pharmacology established in approximately 60 different Brazilian universities.

According to data available at the end of 2009, there are 16 post-graduate programmes in pharmacology in different Brazilian universities, most of them training MSc and $\mathrm{PhD}$ students. Three of these programmes are open for international students and reach high quality according to a triennial evaluation by Coordination for Improvement of Higher Education Personnel (CAPES), an agency of the Brazilian Ministry of Education. In addition to these postgraduate programmes in pharmacology, there are programmes in biochemistry, physiology and pharmaceutical sciences in which researchers contribute to pharmacological research. Successive evaluations by CAPES show that the scientific productivity of Brazilian pharmacologists is rising, both in terms of the number and quality of articles published in peer-reviewed international journals. Surveys derived from the 16 post-graduate programmes in pharmacology indicate that the scientific output of Brazilian pharmacologists in international journals of pharmacology or related fields has increased from approximately 640 publications in 2004-2006 to about 880 in 2007-2009. These numbers do not include the output of pharmacologists working at departments of biochemistry or physiology or in pharmaceutical schools. Further, the 2009 CAPES evaluation showed an increase of $59 \%$ of publications in journals with impact factors $>3.25$, as compared with 2006 .

The wide range of topics investigated by Brazilian pharmacologists as published in Naunyn-Schmiedeberg's Archives of Pharmacology in 2010 is documented by papers on functions of the central nervous system (Boeck et al. 2010; Ribeiro Silva et al. 2010), the cardiovascular system (Montenegro et al. 2010), gastrointestinal and urogenital tract (Klein et al. 2010; Santos et al. 2010), 
immunopharmacology (Dal-Secco et al. 2010; Faria et al. 2010), oncology (Oliveira et al. 2010) and biochemical pharmacology (Cotrim Pimenta et al. 2010). Almost half of those published papers relate to extracts or compounds isolated from Brazilian animals and plants (Klein et al. 2010; Oliveira et al. 2010; Ribeiro Silva et al. 2010; Santos et al. 2010). This is a high percentage as compared to papers typically coming from Western countries, which is only mimicked by submissions from Taiwan and South Korea. Even this high percentage of published papers may be an underestimation of the role of natural products in present Brazilian pharmacology because it does not consider the number of manuscript submissions which do not meet sufficient priority. Unfortunately, many of those natural product-related manuscripts remain rather descriptive, particularly those devoted to pain and inflammation. Frequently, the active constituents of extracts used in animal experiments are unknown and are not or only poorly analyzed or standardized. Hence, the extract often remains a "black box" which limits the usefulness of the data and strongly restricts international research with the extract or compound. Another caveat arises from the frequent lack of in vitro investigations of the extract or compound before it is tested in animal models, which can create two problems. Firstly, while in vivo studies are useful for demonstrating relevance for a physiological endpoint, they often provide limited mechanistic insight, particularly at the molecular and cellular level. In vitro studies often have a greater potential for mechanistic understanding of in vivo observations. Secondly, such "black box" testing in animals without prior extensive in vitro studies would be considered as critical in terms of animal welfare in Western countries. This also holds true for some of the pain and inflammation models which are used in some pain-related natural compound submissions which are in part not recommended by the International Association for the Study of Pain in conscious animals. In addition, control experiments of nervous system side effects which impair testing of pain and inflammation such as sedation and disturbances of motor function are often not provided. Hence, despite the rich potential of future drugs for various health conditions, reviewers and editors will be often faced with a lack of information and difficulty to evaluate the data. Nevertheless, the successful drug development of, e.g. fingolimod (FTY 720) from the mycotoxin, myriocin clearly shows that natural compounds are still a promising source for future drugs even in times of chemical drug design.

In conclusion, the published face of pharmacology is changing and emerging market countries contribute increasingly. Apparently, based upon their local cultures including scientific training and funding schemes which differ from those in highly industrialized countries, emerging country pharmacology tends to favour a different spectrum of research fields in which the exploration of natural products and compounds derived thereof play an important role. This journal welcomes the diversification of pharmacology as a science and will strive to provide a growing presence of colleagues from emerging countries to its editorial board.

Open Access This article is distributed under the terms of the Creative Commons Attribution Noncommercial License which permits any noncommercial use, distribution, and reproduction in any medium, provided the original author(s) and source are credited.

\section{References}

Boeck CR, Martinello C, De Castro AA, Moretti M, Dos Santos Casagrande T, Guerrini R, Calo G, Gavioli EC (2010) Blockade of adenosine A2A receptor counteracts neuropeptide-S-induced hyperlocomotion in mice. Naunyn-Schmiedeberg's Arch Pharmacol 381:153-160

Cotrim Pimenta PH, Cl MS, Noël F (2010) Ivermectin is a nonselective inhibitor of mammalian p-type atpases. NaunynSchmiedeberg's Arch Pharmacol 381:147-152

Dal-Secco D, Freitas A, Abreu MA, Garlet TP, Rossi MA, Ferreira SH, Silva JS, Alves-Filho JC, Cunha FQ (2010) Reduction of ICAM-1 expression by carbon monoxide via soluble guanylate cyclase activtation accounts for modulation of neutrophil migration. Naunyn-Schmiedeberg's Arch Pharmacol 381:483-493

Faria RX, Cascabulho CM, Reis Ram, Alves LA (2010) Largeconductance channel formation mediated by $\mathrm{P} 2 \mathrm{x}_{7}$ receptor activation is regulated through distinct intracellular signaling pathways in peritoneal macrophages and $2 \mathrm{bh} 4$ cells. NaunynSchmiedeberg's Arch Pharmacol 382:73-87

Klein Lc Jr, Becker Gandolfi R, Roberto Santin J, Lemos M, Filho VC, De Andrade SF (2010) Antiulcerogenic activity of extract, fractions, and some compounds obtained from Polygala cyparissias St. Hillaire \& Moquin (Polygalaceae). NaunynSchmiedeberg's Arch Pharmacol 381:121-126

Montenegro MF, Neto-Neves EM, Dias-Junior CA, Ceron CS, Castro MM, Gomes VA, Kanashiro A, Tanus-Santos JE (2010) Quercetin restores plasma nitrite and nitroso species levels in renovascular hypertension. Naunyn-Schmiedeberg's Arch Pharmacol 382:293-301

Oliveira JS, Costa-Lotufo LV, Bezerra DP, Alencar NMN, MarinhoFilho JDB, Figueiredo IST, Moraes MO, Pessoa C, Alves APNN, Ramos MV (2010) In vivo growth inhibition of sarcoma 180 by latex proteins from Calotropis procera. Naunyn-Schmiedeberg's Arch Pharmacol 382:139-149

Ribeiro Silva M, Matos Ximenes R, Martins Da Costa JG, Leal LKAM, De Lopes AA, De Barros Viana GS (2010) Comparative anticonvulsant activities of the essential oils (Eos) from Cymbopogon Winterianus Jowitt and Cymbopogon Citratus (Dc) Stapf. in mice. Naunyn-Schmiedeberg's Arch Pharmacol 381:415-426

Rocha E Silva M, Beraldo WT, Rosenfeld G (1949) Bradykinin, a hypotensive and smooth muscle stimulating factor released from plasma globulin by snake venoms and by trypsin. Am J Physiol 156:261-273

Santos AA Jr, Leal PC, Edelweiss MIA, Lopes TG, Calixto JB, Morrone FB, Campos MM (2010) Effects of compounds Mv8608 and Mv8612 obtained from Mandevilla velutina in the model of hemorrhagic cystitis induced by cyclophosphamide in rats. Naunyn-Schmiedeberg's Arch Pharmacol 382:399-407

Starke K (1998) A history of Naunyn-Schmiedeberg's Archives of Pharmacology. Naunyn-Schmiedeberg's Arch Pharmacol 358:1-109 